\title{
Performance prediction of a single-stage refrigeration system using R134a as a refrigerant by artificial intelligence and machine learning method
}

\author{
Bahadir Erman YUCE a,* (D) \\ a Bitlis Eren University, Department of Mechanical Engineering, TR-13000, Bitlis Turkey
}

\author{
ART ICLE INFO \\ Article history: \\ Received 25 December 2020 \\ Accepted 27 December 2020 \\ Keywords: \\ Artificial neural networks \\ Refrigeration cycle \\ Artificial intelligence \\ Machine learning \\ Thermodynamics
}

Received in revised form 27 December 2020

\begin{abstract}
A B S T R A C T
In this study, COP and heat capacities of evaporator and condenser were calculated by artificial intelligence and machine learning method in a vapor compression mechanical refrigeration cycle using well-known R134a as a refrigerant. Dataset was obtained with CoolPack software to train the model. Evaporating, condensing, superheating and subcooling temperatures are selected as input data. COP, heat capacities of evaporator and condenser are included in the dataset as target values. Artificial Neural Network (ANN) model was created with Matlab R2018b software and validated with target data. The output files obtained were compared with the target files and it was found that the mean square error value was quite close to one. The results of this study show that the ANN method can be used to obtain cycle parameters in one stage refrigeration cycle with high accuracy.
\end{abstract}

\section{Introduction}

People spend $90 \%$ of their time inside building [1]. Fresh air supply is very important in ventilated spaces to provide thermal comfort and sufficient air quality. These outputs are necessary for the occupants, to obtain and maintain specified thermal conditions. Efficiency of office staff and productivity are dependent on the thermal environment conditions [2][3]. If ventilation rates above minimum levels, productivity could be raised and It will pay for itself while decreasing the intensity of SBS (Sick Build Symptoms) symptoms and improving perceived air quality [4]. Ventilation-related energy has an important role in energy consumption. This energy need is increasing and may represent up to $50 \%$ of the building total energy usage, particularly for certain typologies such as office buildings [5].

Cooling units, especially split type air conditioners, are very common in Turkey. Researches that will increase the efficiency of these systems or find the factors that cause them to work inefficiently are very important due to the above-mentioned effects. Artificial intelligence and machine learning is a method that is very popular today, which enables the performance of these and similar thermal systems to be predicted very accurately.

Kılıç [6], investigated estimation of the coefficient of performance (COP) in the transcritical $\mathrm{CO} 2$ one-stage vapor compression cycles with ANN. He compared the ANN results with target data and (R2) value was obtained as 0.99907 . He suggested that ANN model can be used to prediction of the coefficient of performance (COP) in the transcritical CO2 onestage vapor compression cycles.

Hosoz and Ertunc [7], investigated the applicability of ANN to predict various performance parameters like evaporating

\footnotetext{
* Corresponding author.

E-mail address: beyuce@beu.edu.tr

ORCID : https://orcid.org/0000-0002-2432-964X
} 
temperature, compressor power and coefficients of performance for the lower and higher circuits) of a cascade vapor compression refrigeration system. They compared ANN output data with experimental data and ANN output data is agreed well with the experimental target data. They compared ANN output data with experimental data and ANN output data is agreed well with the experimental target data.

Kızılkan et al. [8], investigated the thermodynamic properties such as saturation pressure, liquid and vapor enthalpies, superheated steam enthalpy and temperature of the R410a refrigerant, with Artificial Neural Networks (ANN) method. They used empirical and experimental data available in the literature. They developed new formulations with ANN model to predict the thermodynamic properties of R410a. They said that, these equations obtained from the model were much faster and solutions were simpler.

Yilmaz and Atik [9], performed some experiments about effects of changing cooling water flow rate on the cooling capacity of the mechanical cooling system. They calculated power consumption, thermal efficiency, coefficient of performance (COP) of the system for each scenarios and trained the ANN model. As a result of their work, they stated that artificial neural networks can be used in this field.

There are several studies in the academic literature about artificial intelligence and machine learning and vapor compression mechanical refrigeration cycle. However, all of them examined the subject from a different point of view, and within the knowledge of the author, there is no study similar to this study. R134a is used as refrigerant in this study and ANN model is used to obtain COP and evaporator and condenser capacities.

\section{Methods}

\subsection{Vapor Compression Mechanical Refrigeration Cycle}

The vapor compression mechanical refrigeration cycle shown in Figure 1 consists of four main elements: condenser, evaporator, throttle valve and compressor. It is based on the principle that the refrigerant is mechanically compressed by the compressor as a result of the work given. In this system, the refrigerant compressed to high pressure in the compressor is sent to the condenser as superheated steam. The refrigerant, which condenses by giving heat to the environment, enters the evaporator in wet-vapor state by throttling to low pressure in the throttle valve. The refrigerant, which has a temperature below the ambient temperature surrounding the evaporator, absorbs the heat of the environment, cools the internal environment and is absorbed by the compressor as saturated vapor at the evaporator outlet. [10] The scheme of the vapor compression mechanical refrigeration cycle is given Figure 1.

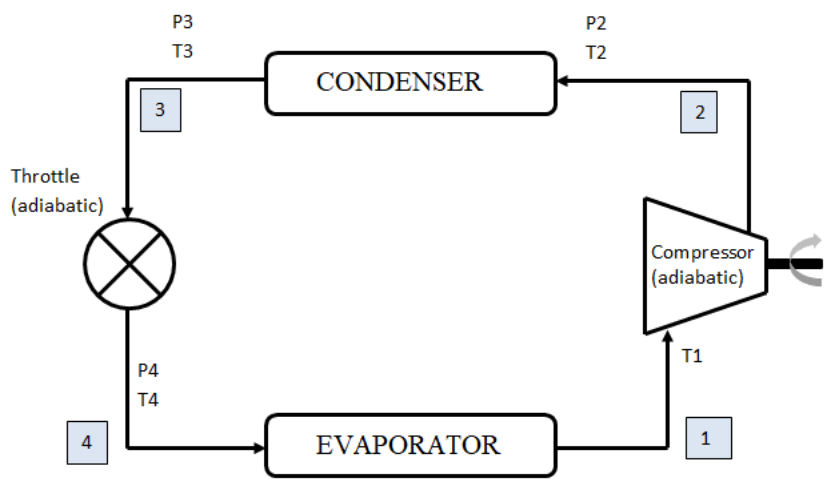

Figure 1. The scheme of the vapor compression mechanical refrigeration cycle

The compressor is adiabatic in this system, Compressor power can be calculates as below:

$$
-w_{k}=h_{2}-h_{1}\left(\frac{k J}{k g}\right)
$$

Heat is extracted at constant pressure in the condenser and condenser capacity is $\left(\mathrm{P}_{2}=\mathrm{P}_{1}=\right.$ constant $)$ :

$$
q_{y}=q_{23}=h_{2}-h_{3}\left(\frac{k J}{k g}\right)
$$

Throttle at constant enthalpy at the throttling valve:

$$
h_{3}=h_{4} \quad \frac{k J}{k g}
$$

Heat transfer to the refrigerant at constant pressure in the evaporator:

$$
q_{b}=q_{41}=h_{1}-h_{4}\left(\frac{k J}{k g}\right)
$$

COP value of the vapor compression mechanical refrigeration cycle:

$$
C O P=\frac{h_{1}-h_{4}}{h_{2}-h_{1}}
$$

56 different COP, $\mathrm{q}_{\mathrm{b}}$ and $\mathrm{q}_{\mathrm{c}}$ values were calculated with CoolPack software according to principles above. R134a was selected as refrigerant. 


\subsection{Artificial Intelligence and Machine Learning}

Artificial neural networks are a system modeled with inspiration to the basis of the human neural [11]. It aims to solve the problems that cannot be solved by classical methods. ANN has important features such as learning, predicting, and making inferences between inputs even if there is missing information. Artificial neural networks, which can perform activities such as prediction, classification, and learning by using the relationship between cells that are linked to each other in the evaluation of complex relationships, are one of the most preferred optimization techniques recently [12].

The ANN model for the one-stage refrigeration cycle was developed using the available dataset obtained from CoolPack software. Dataset consists of 56 rows of input data which include evaporator (Te), condenser (Tc), superheating and subcooling temperatures. Target data of ANN model is COP and heat capacities of evaporator and condenser. $\% 70$ of the data set is applied to ANN model to train it, $\% 30$ of data is used for testing and validating procedures. The scheme of the ANN model for the one-stage cooling cycle is shown in Figure 2. Levenberg-Marquardt algorithm was used in ANN model and weighting coefficients, which is a variant of the back-propagation algorithm, obtained from this algorithm. ANN model is set and computed in Matlab R2018b.

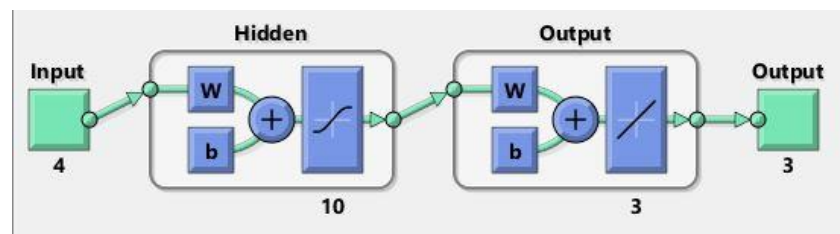

Figure 2. One-stage refrigeration cycle ANN scheme

\section{Results}

Matlab R2018b, Deep Learning Tool, is used to model vapor compression mechanical refrigeration according to ANN method. Wide range of data of Evaporator, condenser, superheat and subcooling temperatures are created in CoolPack and used to train ANN model.

It is important to get highly accurate precited data in these systems to determine the performance of cooling. Performance statement is important not only mechanically but also economically. High performance systems decreases energy consumption. In addition, optimizing system performance will increase thermal comfort and, accordingly, employee productivity. Thus, the dataset obtained from theoretical calculations was used in the training of the ANN model and was used in the retesting of the predictions of this learned model.
The information obtained from this study will be a preliminary evaluation to repeat the study experimentally.

Dataset created in CoolPack imported to ANN model and ANN model was created with Matlab R2018b software. Input and target values was defined. Input, hidden layer, output layer and output can be seen from Figure 2. Evaporator, condenser, superheat and subcooling temperature is the data given to input layer. This layers gives COP and evaporator and condenser capacities. The evaporator capacity of cooling cycle in the dataset is in the range of $178.525 \mathrm{~kJ} / \mathrm{kg}$ to $188.837 \mathrm{~kJ} / \mathrm{kg}$, the condenser capacity is in the range of 215.146 to 237.276 $\mathrm{kJ} / \mathrm{kg}$.

Figure 3 shows the comparison of output COP and target COP. Output values are in a good agreement with target values. $\mathrm{R}^{2}$ is 0.998 . COP is essential for predicting the performance of cooling cycle. ANN model can predict the COP value with high accuracy.

$\mathrm{R}^{2}$ is one of the statistical performance evaluation criteria values and it is also in a good agreement with $\mathrm{q}_{\mathrm{e}}$ target data. It can be seen from Figure 5. $R^{2}$ is 0.999 . predicted $q_{c}$ values are also in a good agreement with target data.

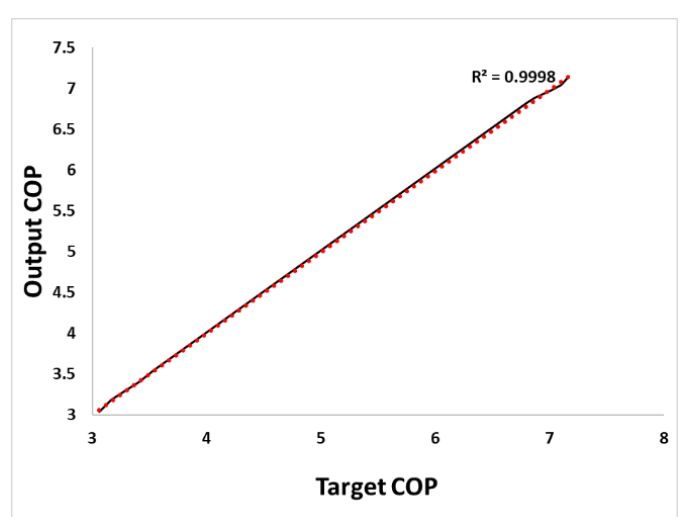

Figure 3. Comparision of output $\mathrm{COP}$ and target $\mathrm{COP}$

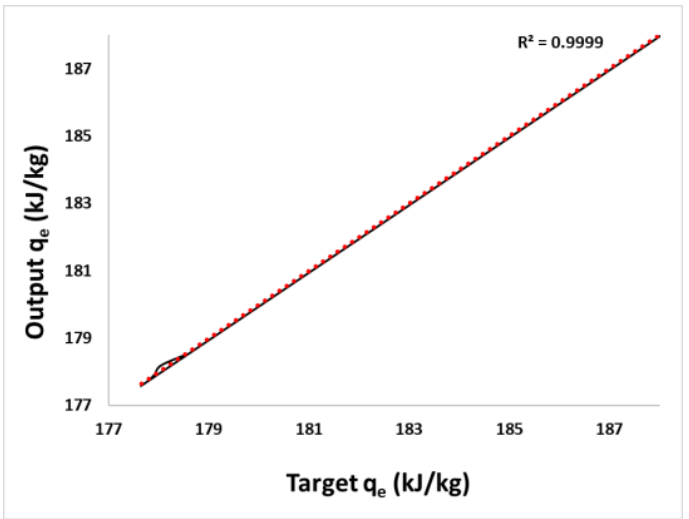

Figure 4. Comparision of output $\mathrm{q}_{\mathrm{e}}$ and target $\mathrm{q}_{\mathrm{e}}$ 


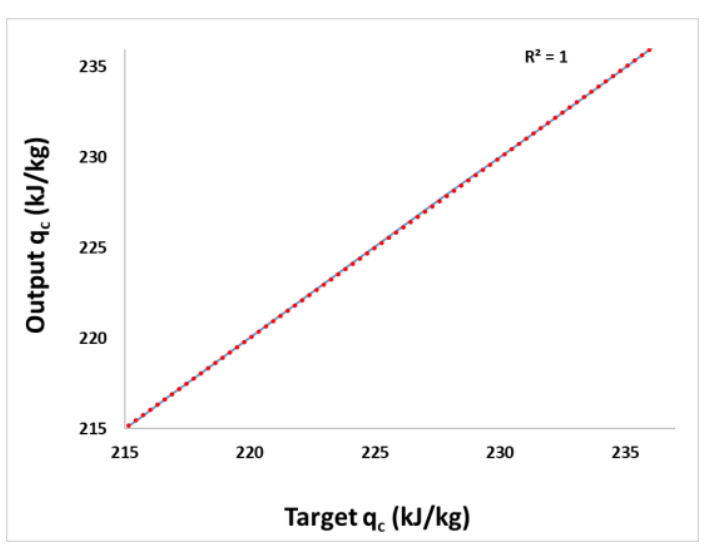

Figure 5. Comparision of output $\mathrm{q}_{\mathrm{c}}$ and target $\mathrm{q}_{\mathrm{c}}$

\section{Conclusions}

In this paper, ANN approach is applied for thermal analysis of vapor compression mechanical refrigeration cycle. The ANN is applied for predicting the coefficient of performance (COP) and evaporator and condenser capacity. Predicted values and target values, which obtained from CoolPack, is compared and results are in a good agreement. It is suggested that ANN model can be applied all refrigerants and other cooling systems. Artificial intelligence and machine learning can be easily applied to thermodynamic cycles and can give fast and reliable results with experimental data.

\section{References}

[1] N.E. Klepeis, W.C. Nelson, W.R. Ott, J.P. Robinson, A.M. Tsang, P. Switzer, J. V. Behar, S.C. Hern, W.H. Engelmann, The National Human Activity Pattern Survey (NHAPS): A resource for assessing exposure to environmental pollutants, J. Expo. Anal. Environ. Epidemiol. 11 (2001) 231-252. doi:10.1038/sj.jea.7500165.

[2] T. Akimoto, S. ichi Tanabe, T. Yanai, M. Sasaki, Thermal comfort and productivity - Evaluation of workplace environment in a task conditioned office, Build. Environ. 45 (2010) 45-50. doi:10.1016/j.buildenv.2009.06.022.
S. ichi Tanabe, M. Haneda, N. Nishihara, Workplace productivity and individual thermal satisfaction, Build. Environ. 91 (2014) 42-50.

doi:10.1016/j.buildenv.2015.02.032.

[4] P. WARGOCKI, D.P. WYON, J. SUNDELL, G. CLAUSEN, P.O. FANGER, The Effects of Outdoor Air Supply Rate in an Office on Perceived Air Quality, Sick Building Syndrome (SBS) Symptoms and Productivity, Indoor Air. 10 (2000) 222-236. doi:10.1034/j.16000668.2000.010004222.x.

[5] P. and C.E.U. European Commission Joint Research Centre, Institute For Health and Consumer Protection, Ventilation, good indoor air quality and rational use of energy, Rep. No. 23, EUR20741 EN. (2003).

[6] B. Kılıç, Alternative Approach For Thermal Analysis Of Transcritical Co2 One-Stage Vapor Compression Cycles, Int. J. Eng. Appl. Sci. 8 (2016) 1-1. doi:10.24107/ijeas.251263.

[7] M. Hosoz, H.M. Ertunc, Modelling of a cascade refrigeration system using artificial neural network, Int. J. Energy Res. (2006). doi:10.1002/er.1218.

[8] Ö. Kizilkan, A.Ş. Encan, K. Yakut, R410A SOĞUTUCU AKIŞKANININ TERMODINA İK ÖZELLIKLERININ YAPAY SINIIR AĞLARI METODUYLA MODELLENMESİ, 21 (2006) 395-400.

[9] S. Yilmaz, K. Atik, Modeling of a mechanical cooling system with variable cooling capacity by using artificial neural network, Appl. Therm. Eng. 27 (2007) 23082313. doi:10.1016/j.applthermaleng.2007.01.030.

[10] R. Yamankaradeniz, İ. Horuz, Ö. Kaynakli, S. Coşkun, N. Yamankaradeniz, Soğutm tekniği ve Isı Pompası Uygulamaları, 3., DORA, Bursa, 2013.

[11] S.A. Kalogirou, Artificial neural networks in renewable energy systems applications: A review, Renew. Sustain. Energy Rev. (2000). doi:10.1016/S1364-0321(01)000065.

[12] H. Yağlı, A. Koç, A. Yapıcı, H.H. Bilgiç, Deneysel Bïr Organik Rankï Çevrimïnde YapaSinir Ağlari (Ysa) Yardimiyla Güç Tahmini, Selcuk Univ. J. Eng. ,Science Technol. 4 (2016) 7-7. doi:10.15317/scitech.2016116091. 